\title{
A Study of Moisture Content of Lubricating Oil Based on Impedance Analysis
}

\author{
Liao Qiang \\ College of Mechanical Engineering \&The State Key \\ Laboratory of Mechanical transmission, Chongqing \\ University,Chongqing, P.R.China 400044 \\ 1q922@163.com
}

Chen Lili

College of Mechanical Engineering

Chongqing University

Chongqing, P.R.China 400044

\author{
Wu Jiang \\ College of Mechanical Engineering \\ Chongqing University \\ Chongqing, P.R.China 400044 \\ wujiang890109@163.com \\ Li Xiaowei \\ College of Mechanical Engineering \\ Chongqing University \\ Chongqing, P.R.China 400044
}

\begin{abstract}
As one of the main factors of lubricant contamination, moisture can cause the failures and life reduction of mechanical devices. For the purpose of replacing the polluted oil timely, a method of rapid detection of the moisture content is needed. By studying the measurement conditions including perturbation amplitude, scanning frequency and test time, this paper presents the impedance method to achieve that. Results from this study show when the perturbation amplitude exceed $1 \mathrm{~mA}$ and the measurement frequency ranges from $5 \mathrm{kHz}$ to $10 \mathrm{kHz}$, impedance method can get fast and accurate determination of moisture content of the oil in the first minute. Besides, mathematical models about the relationship between impedance and moisture content have been established.
\end{abstract}

Keywords-impedance method; measuring conditions; moisture content

\section{INTRODUCTION}

Lubricating oil plays an important role in reducing friction coefficient, cooling, preventing metal surface corrosion, cleaning and sealing in most mechanical equipments. For these mechanical equipments, the normal work of lubrication system plays the vital role in the safe and economic operation. The moisture is one of the main factors leading to oil pollution, and it is harmful for mechanical equipments. In order to ensure the safe and stable operation, timely and accurate detection of water content in oil has great significance $[1,3]$.

Moisture in the lubricating oil can emulsify the oil, reduce viscosity and oil film strength and even accelerate the oxidative deterioration of oil. The moisture in oil mainly exists in three forms in oil, which are named free water, emulsifying water and dissolved water. The moisture detection is an important index in routine monitoring. Several kinds of methods are widely used in measuring the moisture content of lubricating oil, and each of these approaches has advantages and drawbacks. In this paper, impedance method for determination of moisture content of lubricating oil was mainly studied.

\section{MATERIAL AND METHODS}

\section{A. Instrument equipment}

The experimental devices consist of the Agilent 4294A precision impedance analyzer, 16452 liquid test fixture, crossover cable, computer, $10 \mathrm{ml}$ small beaker, pipette, electronic analytical balance, and other components.

\section{B. Test method to design}

At present, there are several methods for measuring the moisture content of lubricating oil which are classified into three main types $[1,3,4]$.

1) Laboratory analysis methods: Lubricating oil water measurement under laboratory conditions mainly include gravimetric method, distillation and Carl-Fischer method which has been widely adopted because of the advantages of accuracy, repeatability, and rapid measurement.

2) Spectral analysis methods: Spectral analysis methods include atomic emission spectrometry, atomic absorption spectrometry, infrared spectroscopy and X-ray fluorescence spectrometry. Spectrometer equipments are expensive, and the strict installation conditions also prevent them from promoting the production site. Therefore, they are used to analyze impurity of the oil in concentration.

3) Electrical analysis methods: Electrical analysis methods mainly include two types. Online resistive monitoring instruments mainly use the theory that different grits have different resistivity and contaminants of the oil are considered as the dielectric in capacitance method. The different content of impurity in oil will affect the dielectric constant.

Based on the electrical methods, this paper puts forward a creative method to detect the moisture content of lubricating oil through applying a small amplitude current to 
the electrode of the fixture. The moisture in the oil will change the resistivity and dielectric constant of the lubricating oil with which impedance varies. According to the moisture content for oil drain with GB/T260, the lubricating oil should be replaced when the moisture content is more than 0.2 percent [4]. Therefore impedance of different kinds of lubricating oil was discussed in this paper.

At first, the experiment about the feasibility analysis of the impedance measurement was operated: two brands of lubricating oil (SKALN 32\# turbine oil and Shell 5w-30 engine lubricating oil) which have the same moisture content were prepared to compare their differences, and then one kind of oil was selected to observe the alteration of impedance characteristic through changing the spacer of the test fixture [2]. After that, a series of experiments were conducted to discuss the determination of the optimum measurement conditions including perturbation amplitude, measuring frequency and measuring time. The tests consist of 8 samples with different water content, followed by $0 \%$, $0.1 \%, 0.2 \%, 0.5 \%, 0.75 \%, 1.25 \%, 2.5 \%, 5 \%$.Each set of test lasts for 5 minutes and scanning frequency ranges from 100 $\mathrm{Hz}$ to $100 \mathrm{kHz}[4,5]$.

\section{RESULTS AND DISCUSSION}

\section{A. Feasibility analysis of impedance measurement of} moisture content

In order to prove that different lubricant have different impedance characteristics, in the beginning of this experiment, two kinds of different brands of lubricant were compared. The impedance spectrum chart was plotted as follows.

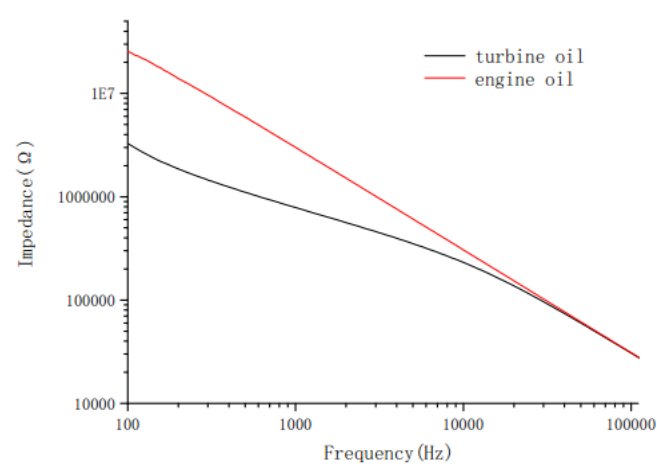

Figure 1.Impedance for two oils in different frequency

Figure 1 shows that impedance characteristics of the two brands of lubricant have significant distinction. It's easy to know that different kinds of lubricating oil have different additive which would cause different electrical characteristic of two oils and it can account for that case. [1,6]Therefore, it can be speculated that the different composition of lubricating oil lead to the different impedance characteristics. Then, for the same moisture content of Shell engine lubricating oil, experiment research on volume was performed and processed, as shown in figure 2.



Figure 2.Impedance of engine oil with different volume

Image above indicates that alteration of lubricating oil volume causes obvious difference of impedance, besides, relationship between impedance and volume is linear and the oil impedance characteristics meet up with the characteristics of liquid .Therefore, impedance measurement is possible to distinguish the lubricant of different composition.

\section{B. The determination of the optimum measurement conditions}

1) The impact of the perturbation amplitude:

In order to analyze the impact of the perturbation amplitude, three fixed frequency were selected to analyze the impedance of lubricant under the condition that the measuring current ranges from $200 \mu \mathrm{A}$ to $20 \mathrm{~mA}$. The test result was illustrated in Figure 3.





Figure 3.Impedance influenced by different perturbation amplitude

The illustration above shows that impedance of lubricating oil has little fluctuation when the current is above $1 \mathrm{~mA}$, and the larger the perturbation amplitude is, the smaller the fluctuation is. That is to say, the experiment should be operated in higher current so as to decrease the impact of the perturbation amplitude. Therefore, the final current was set at $20 \mathrm{~mA}$ which is the largest value the instrument can provide.

2) The effect of different measuring frequency:

Generally speaking, the impedance of liquid varies with the frequency. In order to compare the 8 kinds of lubricating oil of different moisture content, and analyze the distinction of their impedance, the experimental data were plotted as follows.

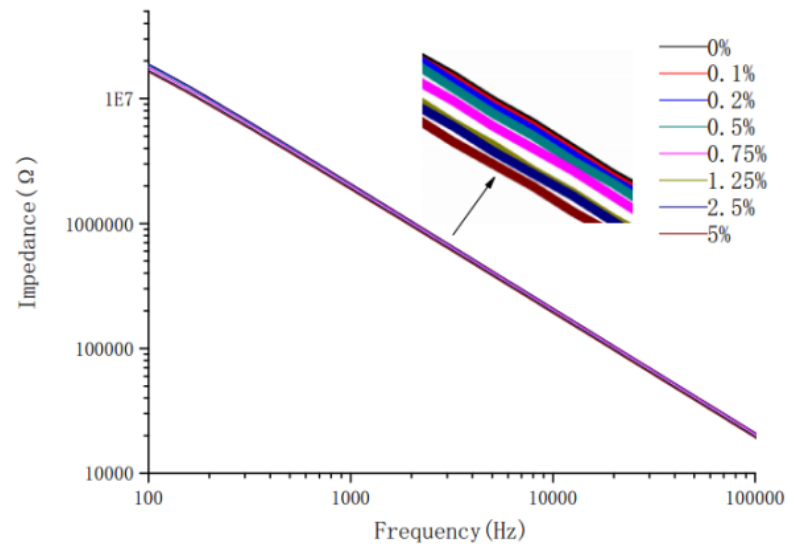

Figure 4.Impedance of 8 kinds of oil in 1st minute

Figure 4 indicates that impedance decreases with the increase of frequency for each kind of oil, but the distinction between two adjacent curves change as well. In order to find the best frequency to distinguish the different kinds of lubricating oil, the correlation between moisture content and impedance should be analyzed. The measuring frequency ranges from $100 \mathrm{~Hz}$ to $100 \mathrm{kHz}$, so 30 evenly distributed points from all frequency bands were analyzed by SPSS 19.0. The analysis table was shown in Table 1 .
TABLE 1 CORRELATION BETWEEN IMPEDANCE AND MOISTURE CONTENT

\begin{tabular}{|c|c|c|c|}
\hline $\begin{array}{c}\text { Frequency } \\
(\mathrm{Hz})\end{array}$ & $\begin{array}{c}\text { Correlation } \\
\text { coefficient }\end{array}$ & $\begin{array}{c}\text { Frequency } \\
(\mathrm{Hz})\end{array}$ & $\begin{array}{c}\text { Correlation } \\
\text { coefficient }\end{array}$ \\
\hline 104 & -0.8606 & 6012 & -0.9235 \\
\hline 202 & -0.8847 & 7362 & -0.9245 \\
\hline 303 & -0.8894 & 8146 & -0.9212 \\
\hline 410 & -0.8983 & 9014 & -0.9235 \\
\hline 502 & -0.8923 & 10494 & -0.9273 \\
\hline 615 & -0.9019 & 11039 & -0.9269 \\
\hline 716 & -0.9041 & 20267 & -0.9233 \\
\hline 834 & -0.9042 & 30389 & -0.9215 \\
\hline 923 & -0.9035 & 41176 & -0.9217 \\
\hline 1021 & -0.9064 & 50421 & -0.9252 \\
\hline 1130 & -0.908 & 61740 & -0.9212 \\
\hline 2076 & -0.9187 & 71868 & -0.9217 \\
\hline 3113 & -0.9196 & 83657 & -0.9233 \\
\hline 4009 & -0.9233 & 92573 & -0.9234 \\
\hline 5165 & -0.9231 & 102440 & -0.9219 \\
\hline
\end{tabular}

The table indicates that the frequency ranging from $5 \mathrm{k}$ $\mathrm{Hz}$ to $10 \mathrm{kHz}$ shows the better correlation, so it can be speculated that this frequency band has closer relationship between impedance and moisture content and it should be selected to make mathematical models of the relationship between impedance and moisture content.

\section{3) The effect of measuring time:}

The optimum frequency band has been studied already and after that, taking the impact influenced by the increase of measuring time into consideration is the next thing. Take $5 \mathrm{kHz}$ as example, 8 kinds of moisture content of lubricating oil were compared to represent variation of impedance over time, as shown in the figure below.

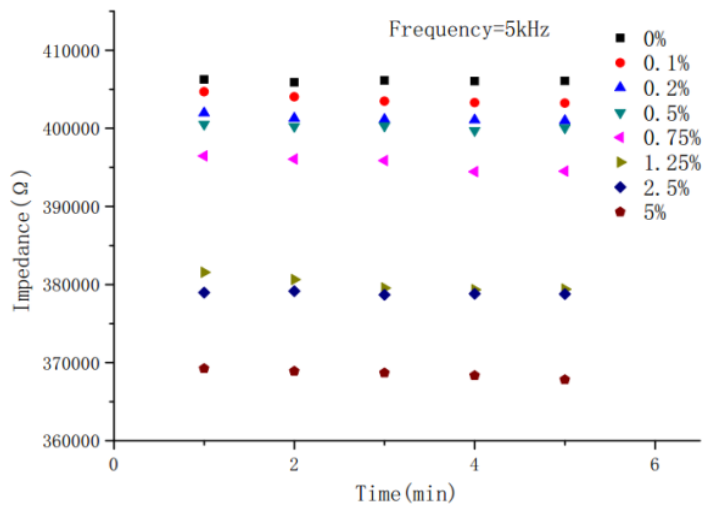

Figure 5.Time-evolution of different kinds of oil

The picture above shows that impedance for each kind of lubricating oil of different moisture content varies little over time. And the difference between the different oil in the first minute is significant. Therefore, data collected in the first minute should be a priority so as to distinguish them faster. 


\section{Analysis of relationship between impedance and moisture content}

According to the analysis above, the final test condition has been studied yet. Thus data in the first minute were gathered, as shown in the figure 6 .

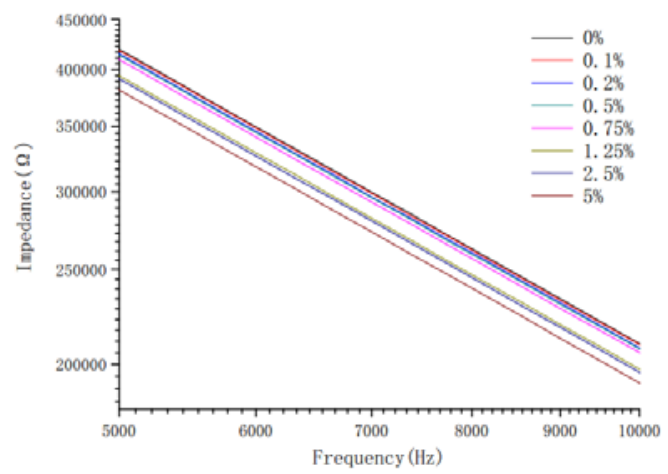

Figure 6.Impedance of different kinds of oil

The illustration above shows significant differences of impedance characteristic with the increase of moisture content. Overall, impedance is in inverse ratio to the moisture content. The relationship between impedance and moisture content can be built to describe the actual effect on lubricating oil that influenced by moisture [7].

For this frequency band, correlation between impedance and moisture is much more closer as a whole, so any frequency could be selected to make mathematical models of the relationship. Therefore, 6 points were selected as the characteristic frequencies to fit the equation of two variables. The fitting equations were given in the following table.

\section{TABLE 2 EQUATION BETWEEN IMPEDANCE AND MOISTURE} CONTENT

\begin{tabular}{cc}
$\begin{array}{c}\text { Freq } \\
\text { uenc } \\
\mathbf{y} \\
\mathbf{( H z})\end{array}$ & Fitting equation \\
\hline & $y=407334.11421-22864.46724 \mathrm{x}+5776.55054 \mathrm{x}^{2}-544.88554 \mathrm{x}$ \\
5165 & $y=349964.66975-19312.5804 \mathrm{x}+4811.8512 \mathrm{x}^{2}-448.13226 \mathrm{x}$ \\
6012 & \\
& $y=286097.05952-15376.19475 \mathrm{x}+3725.56277 \mathrm{x}^{2}-341.07263 \mathrm{x}$ \\
7362 & \\
8146 & $y=258549.13286-13847.02896 \mathrm{x}+3339.95402 \mathrm{x}^{2}-301.9696 \mathrm{x}$ \\
& $y=233733.8526-12799.87353 \mathrm{x}+3222.92404 \mathrm{x}^{2}-304.30224 \mathrm{x}$ \\
9014 & \\
1049 & $y=200803.48789-10439.03904 \mathrm{x}+2452.85961 \mathrm{x}^{2}-219.82726 \mathrm{x}$ \\
4 & \\
\hline
\end{tabular}

Where y represents impedance of lubricating oil of different moisture content, $\mathrm{x}$ represents moisture content of lubricating oil.

For each equation, it can be used to evaluate the pollution level of lubricating oil. According to national standard $\mathrm{GB} / \mathrm{T} 260$, impedance method can reflect whether it is needed for replacing the oil through these equations. Because of the statistic error, the system error and the error of data processing, the equation needs to be corrected through a large number of experiments combined with the requirement of industry.

\section{CONCLUSIONS}

Moisture can change the electrical properties of lubricating oil. As a result, impedance varies obviously with the increase of moisture content. Through a series of experiments about the optimum measurement conditions including perturbation amplitude, scanning frequency and test time, results show that, the test data is more stable if the perturbation amplitude is greater than $1 \mathrm{~mA}$, correlation coefficient between impedance and moisture content is less than -0.92 when the frequency ranges from $5 \mathrm{k} \mathrm{Hz}$ to $10 \mathrm{KHz}$, and impedance method can get fast and accurate determination of water content of the oil in the first minute. Equations about the relationship between impedance and moisture content have been established, and this relationship can be used to analyze the pollution level of lubricating oil. Moreover, much more studies with improved experimental designs are still needed to go on evaluating this method.

\section{REFERENCES}

[1] Wang Shuanglin, Research of Measuring Method on the Trace Water in Lubricating oil[D], Northeastern university, January 2006.

[2] Li Yujie, Tian Hongxiang,Han Qiuping,Research on Monitoring Water Content in Lubricating Oil Based on Capacitive Sensor[J] , Metrology \& Measurement Technique,2011(38.8),pp,34.35.37.

[3] Li Hongqi, Study on the On-line Inspection Method of Vehicle Lubricant Based on the Technology of Dielectric Coefficient[D], Jilin:University, 2007.

[4] Gong Pei, Liu Xiangxuan, Guo Lei, Gao Xin,Peng Jihong, Rapid Analysis of Water Content in Lubricant Oil Based on the Dielectric Constant[J], Lubricating Oil, Vol. 36 Nov. 2011,pp,97,98,99.

[5] Li Xiwu,Su Jian,Liu Yumei.Technology for Monitoring Automotive Engine Lubricating Oil by Dielectric Constant Method[J]. 2011.10(46), pp, 831-835

[6] Liu Kai, Oil Monitoring Method Based on theDielectric Constant[J], LUBRICATION ENGINEERING, 2009.1(34), pp, 94-96.

[7] Wang Hailin,Yin Huan,Luo Wenhao,Luo Kuo. Study on Relationship Between Chemical Indicators and Permittivity of Engine Lubricating Oil[J]. Journal of Chongqing University of Technology. 2010.1(24), pp.13-17. 